\title{
INFESTAÇÃO DE Mimosa gemmulata Barneby EM ÁREAS ENTRE TALHÕES DE EUCALIPTO DE CERRADO EM SUCESSÃO SECUNDÁRIA ${ }^{1}$
}

\author{
José Eduardo Vargas Lopes Araújo², Carlos Victor Mendonça Filho³, José Barbosa Santos ${ }^{4}$ e Felipe \\ Paolinelli Carvalho ${ }^{5}$
}

\begin{abstract}
RESUMO - Observam-se no Brasil extensos plantios de eucalipto, sobretudo no Estado de Minas Gerais, que possui essa cultura como atividade rentável em áreas marginais. Visando reduzir os efeitos da colheita florestal sobre a vegetação nativa e seleção de algumas espécies como o angiquinho (Mimosa gemmulata Barneby), objetivouse com este trabalho avaliar a sucessão secundária em povoamentos de eucalipto de diferentes idades e manejo após a exploração, comparando-a por meio da composição florística e estrutura horizontal e vertical da vegetação arbustivo-arbórea, com fragmentos de Cerrado. O trabalho foi realizado em área representativa do referido bioma no Vale do Jequitinhonha. Foram calculados os parâmetros fitossociológicos e os índices de diversidade e da similaridade em ambientes com recuperação inicial e avançada, com e sem eucalipto. O controle foi o Cerrado sentido restrito. Foram amostrados 42 famílias, 99 gêneros, 150 espécies e 1268 indivíduos. O estudo da composição florística e dos parâmetros fitossociológicos indicou a existência de famílias, gêneros e espécies de grande relevância na área que são típicos do bioma Cerrado. A remoção do eucalipto na regeneração inicial não afetou a diversidade nesses ambientes. Contudo, a remoção do eucalipto no estádio avançado promoveu redução da diversidade, permitindo a colonização pela espécie pioneira Mimosa gemmulata Barneby. No entanto, a manutenção do eucalipto na recuperação avançada resultou em maiores valores de diversidade e demais atributos estruturais. Os resultados deste estudo subsidiarão as práticas de manejo a serem adotadas em áreas similares, visando à manutenção da diversidade biológica nos locais de reestabelecimento de corredores de biodiversidade entre áreas cultivadas.
\end{abstract}

Palavras-chave: Angiquinho; Fitossociologia; Monocultura.

\section{COLONIZATION OF Mimosa gemmulata Barneby ON AREAS AMONG EUCALIPTOUS STANDS OF CERRADO IN SECONDARY SUCCESSION}

\begin{abstract}
Extensive eucalyptus plantations are observed in Brazil, especially in Minas Gerais State, which has this culture as a profitable activity in marginal areas. Trying to reduce effects of forest harvest on native vegetation and selection of some species as angiquinho (Mimosa gemmulata Barneby), this study aimed to evaluate secondary succession in eucalyptus stands of different ages and managements after exploration, the floristic composition and horizontal and vertical structure of shrub-arboreal was compared with fragments of Cerrado. The work was conducted in a representative area of this biome on Vale do Jequitinhonha. Phytosociological parameters and the indexes of diversity and similarity were calculated at the environments with initial and advanced recuperation, with and without eucalyptus. Control environment was Cerrado restricted sense. There were samples of 42 families, 99 genera, 150 species and 1268 individuals. Floristic composition and phytosociological parameters indicated existence of families, genera and species of great relevance, typical of Cerrado. Removing eucalyptus at initial regeneration did not affect diversity. However, removing at advanced stage provided diversity reduction, permitting colonization by pioneer species as Mimosa gemmulata Barneby. On the other
\end{abstract}

\footnotetext{
${ }^{1}$ Recebido em 06.07.2012 aceito para publicação em 29.04.2014.

${ }^{2}$ Universidade Federal dos Vales do Jequitinhonha e Mucuri, UFVJM, MG, Brasil. E-mail:<duvargas@gmail.com>.

${ }^{3}$ Departamento de Ciências Biológicas, Universidade Federal dos Vales do Jequitinhonha e Mucuri, Diamantina, MG, Brasil. E-mail: <cvmendonca@gmail.com>.

${ }^{4}$ Departamento de Agronomia, Universidade Federal dos Vales do Jequitinhonha e Mucuri, Diamantina, MG, Brasil. E-mail:

<jbarbosasantos@yahoo.com.br>.

${ }^{5}$ Universidade Federal de Viçosa, UFV, MG, Brasil. E-mail:<felipepaolinelli@yahoo.com.br>.
} 
hand, maintaining eucalyptus at advanced recuperation resulted in higher values of diversity and other natural attributes. Results will subsidize management practices to be adopted in similar areas, aiming biological diversity maintenance in sites used in biodiversity corridor reestablishment among cultivated areas.

Keywords: Angiquinho; Phytosociology; Monoculture.

\section{INTRODUÇÃO}

O Vale do Jequitinhonha caracteriza-se por ser uma das regiões de menor Índice de Desenvolvimento Humano do Brasil (BRASIL, 1997), em parte devido às condições edafoclimáticas adversas. O surgimento do plantio de extensas áreas de monocultivo de eucalipto no Médio Jequitinhonha, por empresas de bioenergia, tornou-se uma das principais opções de renda e empregos da região. Contudo, o plantio realizado no passado, sem critérios ambientais, resultou na ampla remoção da vegetação nativa e na redução da biodiversidade, diminuindo a qualidade ambiental. Em regiões de importante diversidade biológica, como o Cerrado, são necessários estudos relacionados à biologia e ecologia de espécies que invadem essas áreas, sobretudo em consequência dos reflexos negativos sobre a biodiversidade local e regional (PEDRALLI, 2003; RAMSAR, 2004). Tais consequências tornam essas plantas como daninhas nos locais onde proliferam (SANTOS et al., 2005).

No sistema de monocultivo do eucalipto até seu completo estabelecimento, observam-se espaços e recursos a serem explorados, facilitando a ocupação pelas plantas daninhas (SOUZA et al., 2003). Considerando-se o lento desenvolvimento da cultura, a sucessão das espécies na própria área e no entorno após a retirada do produto comercial pode ser comprometida pela agressividade de algumas infestantes monodominantes. Para avaliar a sucessão ecológica, outros estudos têm abordado os parâmetros fitossociológicos em estandes de diferentes idades. Com a maturação dos estandes, a diversidade de espécies aumenta, principalmente, pela competição entre espécies dominantes por recursos como luz e nutrientes do solo (FINEGAN, 1984).

Paula et al. (2004), estudando a sucessão em área de floresta atlântica após 14 anos do primeiro levantamento, ressaltaram a importância da variação diamétrica para o entendimento dos processos sucessionais. Esses autores não encontraram variação na densidade absoluta de espécies pioneiras e secundárias iniciais, mas, sim, para espécies secundárias tardias. Esses fatos demonstram melhoria nas condições de suporte da área para os grupos ecológicos mais avançados na escala sucessional. Oliveira-Filho et al. (2004) analisaram a regeneração após 15 e 40 anos de desmatamento realizado em floresta secundária, visando detectar as diferenças na composição e diversidade de espécies e na estrutura de estandes, observaram alta densidade nos estandes mais jovens, nenhuma diferença significativa na área basal e volume por hectare entre estandes e maior abundância de espécies tolerantes à sombra nos estandes mais antigos.

O estudo de cronossequências comparando estandes jovens e antigos após algum impacto anterior (fogo, desmatamento etc.) é um método útil para a caracterização dos processos regenerativos e da sucessão de espécies, como tem sido comprovado por vários autores (BROWN; LUGO, 1990; GRAU et al., 1997; RIBAS et al., 2003). Contudo, nenhum estudo aplicou essa abordagem para áreas anteriormente exploradas com monocultivo de eucalipto.

Empresas implementam o estabelecimento de corredores ecológicos que ligam as áreas de preservação com o intuito de elevar a biodiversidade das reservas nativas, particularmente em áreas onde são encontrados mosaicos de vegetação como observado no bioma do Cerrado (RIBEIRO; WALTER, 1998), tomadas ao redor pelos extensos plantios de eucalipto. Nessas áreas, a ocorrência de espécies monodominantes - daninhas - tem sido relatada, tornando-se as áreas impróprias à recuperação.

Do ponto de vista agronômico, o conhecimento da estrutura de uma comunidade de plantas daninhas é muito importante. Antes de determinar o programa de controle, é necessário estabelecer uma ordem de prioridades entre as espécies presentes. As espécies predominantes, pela sua abundância e nocividade, deverão receber atenção especial, concentrando quase todos os esforços de controle. Embora as espécies secundárias não requeiram atenção individualizada, mas que não se deve ignorar sua presença (FERNÁNDEZ-QUINTANILLA et al., 1991). Há exemplos de inversão das importâncias relativas das 
espécies devido à adoção de métodos de controle (MONQUERO; CHRISTOFFOLETI, 2003) e à alteração no sistema de cultivo (VOLL et al., 2001) ou no esquema de rotação de culturas (BUHLER et al., 1997).

O gênero Mimosa constitui tema relevante para estudo em face de sua complexidade, resultante da grande diversidade morfológica, certamente relacionada à ampla distribuição geográfica e aos diferentes tipos de hábitat em que ocorre. Em algumas áreas cultivadas com eucalipto, tem sido observada, após o corte, elevada infestação do angiquinho (Mimosa gemmulata), espécie favorecida principalmente pela sua morfologia, apresentando vários ramos perfilhando desde a base e também pela forma de dispersão das sementes. Além da monodominância promovida pela espécie, tem sido relatada sua capacidade de ocorrer em áreas abertas, com maior intensidade de competição por água do que por luz (BARNEBY, 1991). Suas plantas com características pioneiras, via de regra, possuem grande agressividade caracterizada por elevada e prolongada capacidade de produção de diásporas dotadas de alta viabilidade e longevidade, que são capazes de germinar, de maneira descontínua, em muitos ambientes.

Objetivou-se com este trabalho avaliar a sucessão secundária em povoamentos de eucalipto de diferentes idades e manejo após a exploração, comparando-a por meio da composição florística e estruturas horizontal e vertical da vegetação arbustivo-arbórea, com fragmentos de Cerrado.

\section{MATERIAL E MÉTODOS}

O estudo foi realizado em área de reserva legal de aproximadamente 463 ha de Cerrado, situada no Alto Vale do Rio Jequitinhonha, entre as coordenadas $17^{\circ} 44^{\prime} 30^{\prime \prime}$

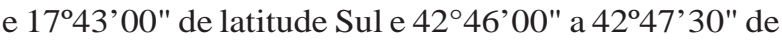
longitude Oeste (WGR). O relevo é caracterizado por áreas aplainadas, ou suavemente onduladas, denominadas regionalmente por "Chapadas" com altitudes médias em torno de $900 \mathrm{~m}$, que se alternam com áreas dissecadas, que acompanham os maiores cursos d’água, em que predominam vertentes ravinadas e colinas. Os solos dominantes são os latossolos: Latossolo Vermelho, Latossolo Vermelho-Amarelo, Latossolo Amarelo e Latossolo Acinzentado, todos distróficos ou álicos e de textura argilosa ou muito argilosa. Nas vertentes ravinadas e no terço inferior das encostas ocorrem Plintossolos e Plintossolos Pétricos, enquanto nos estritos terraços fluviais são encontrados Gleissolos.
O clima da região é do tipo Cwb (tropical de altitude), segundo a classificação de Köppen, com média anual de precipitação de $1.081 \mathrm{~mm}$, verões chuvosos e invernos secos e temperatura anual média de $20,1^{\circ} \mathrm{C}$, variando de 16,3 a $23,8{ }^{\circ} \mathrm{C}$ entre os meses extremos.

A vegetação encontrada é composta por formações savânicas, predominantemente de Cerrado senso estrito (RIBEIRO; WALTER, 1998), sendo também encontradas manchas de Floresta Estacional Semidecidual. Para avaliar o estádio de recuperação de faixas de reserva legal entre plantios florestais e o efeito da presença dos eucaliptos remanescentes e de sua remoção, foi realizado um inventário em cinco ambientes, com quatro repetições e parcela experimental de 20 x 20 m (400 $\mathrm{m}^{2}$ ), sendo: recuperação inicial com e sem eucalipto em estágio de sucessão menor que três anos (RICE e RISE, respectivamente); recuperação avançada com e sem eucalipto em estágio de sucessão maior que três anos (RACE e RASE, respectivamente); além da testemunha (controle), composta pelo Cerrado sentido restrito em estágio sucessional avançado.

Nas parcelas de Cerrado e em todas as parcelas de recuperação, amostraram-se os indivíduos medidos a $30 \mathrm{~cm}$ do solo também superior ou igual a $3 \mathrm{~cm}$. Todas as bifurcações acima de $30 \mathrm{~cm}$ de altura foram medidas separadamente e, posteriormente, fundidas. Para cálculo da área da secção do tronco do indivíduo, foram somadas as áreas seccionais de todos os troncos medidos (PINHEIRO; DURIGAN, 2012).

Para cada indivíduo, além do diâmetro, foi também estimada a altura, com o auxílio de uma vara de $3 \mathrm{~m}$, graduada de 10 em $10 \mathrm{~cm}$. Foram realizadas coletas de material botânico para posterior identificação taxonômica das espécies. O material coletado foi processado dentro dos métodos usuais em botânica (FORMAN; BRIDSON, 1989) e identificado com o auxílio de chaves taxonômicas, consultas à bibliografia específica, contatos com especialistas e comparações em herbários. O material foi incorporado ao herbário da Universidade Federal dos Vales do Jequitinhonha e Mucuri (DIAM). Duplicatas foram enviadas ao herbário da Universidade de Brasília (UnB). As espécies foram listadas nas respectivas famílias de acordo com APG III (2009).

Foram analisados os seguintes parâmetros fitossociológicos das espécies: densidade, frequência e dominância, nos seus valores absolutos e relativos, além de calculados os índices de valor de cobertura 
e importância, sendo os dados processados de acordo com Felfili e Silva Junior (2003):

- Densidade absoluta $(\mathrm{DA})=\left(n_{i} / a ́ r e a\right)$

- Densidades relativa $(\mathrm{DR})=\left(n_{i} / N\right) 100$

- Frequência absoluta $(\mathrm{FA})=\left(P_{i} / P\right) 100$

- Frequência relativa $(F R)=(F A / F A) 100$

- Dominância absoluta (DoA) $=\left(g_{i} /\right.$ área $) 100$

- Dominância relativa $(\mathrm{DoR})=\left(g_{i} / G\right) 100$

- Índice de valor de importância $(I V I)=\left(D R_{i}+\right.$ $\left.F R_{i}+D_{o}\right) / 3$

em que ni $=$ número de indivíduos da espécie $\mathrm{i}$; área = área total amostrada; $\mathrm{N}$ = número total de indivíduos; $\mathrm{Pi}$ = número de parcelas com ocorrência da espécie $\mathrm{i}$; $\mathrm{P}=$ número total de parcelas; $\mathrm{FAi}=$ frequência absoluta da espécie i; FA = somatória das frequências absolutas de todas as espécies; gi = área basal da espécie i; G = somatória das áreas basais de todas as espécies; DRi = densidade relativa da espécie i; FRi = frequência relativa da espécie i; e DoRi = dominância relativa da espécie i. A estrutura vertical da vegetação também foi caracterizada por meio da distribuição dos indivíduos por classes de diâmetro e de altura.

Foram também calculados os índices de diversidade de Shannon-Weaver ( $\mathrm{H}^{\prime}$ ) e de equabilidade de Pielou (J'), por meio das respectivas fórmulas:

$$
\begin{aligned}
& J^{\prime}=H^{\prime} / 1 \mathrm{n} S \\
& H^{\prime}=-\Sigma p_{i} 1 \mathrm{n} p_{i}
\end{aligned}
$$

em que pi é igual à proporção do número de indivíduos da espécie i em relação ao total de indivíduos, H' é o índice de diversidade Shannon-Weaver e S, o total de espécies amostradas.

\section{RESULTADOS}

Foram amostradas 42 famílias, 99 gêneros e 150 espécies, compreendendo 1.268 indivíduos. As famílias que apresentaram maior número de espécies foram Fabaceae (14,94\%), Myrtaceae (13,64\%), Malpighiaceae (5,84\%), Asteraceae e Melastomataceae (4,55\%) e Rubiaceae e Lauraceae (3,90\%).
Na Tabela 1 são apresentadas as espécies e seus parâmetros fitossociológicos, nos diferentes ambientes, onde estão amostradas as espécies responsáveis por mais de 50\% do índice de valor de importância (IVI). Mimosa gemmulata (angiquinho), da família Fabaceae, foi a espécie com maior índice de valor de importância em três ambientes, RISE, RICE e RASE, principalmente neste último (Tabela 1), podendo ser considerada infestante agressiva. Entretanto, essa espécie não foi encontrada nos ambientes RACE e Cerrado.

Na Tabela 2 é apresentada a síntese dos parâmetros gerais de estrutura e diversidade entre os diferentes ambientes. Nessa síntese em RASE e RACE, foi detectado maior número de indivíduos, maior densidade absoluta e maior área basal por hectare, em comparação com os tratamentos iniciais, provavelmente resultado do processo sucessional. O tratamento RASE, em que se constatou maior índice de velocidade de importância (Tabela 1), apresentou o menor índice de diversidade e de equabilidade (Tabela 2).

\section{DISCUSSÃO}

Na composição florística das áreas estudadas das 10 famílias mais importantes, cinco também se destacaram na lista das espécies fanerogâmicas do Cerrado, elaborada por Mendonça et al. (1998), entre elas: Fabaceae, Myrtaceae, Rubiaceae, Asteraceae e Melastomataceae. Famílias de destaque como Malpighiaceae, Myrsinaceae e Vochysiaceae também foram importantes no estudo de Neri et al. (2007) sobre o Cerrado de Senador Modestino Gonçalves, região próxima da área de estudo. Entre os principais gêneros, mereceram destaque Myrcia com sete espécies, Eugenia e Ocotea com seis e Byrsonima e Miconia com cinco, além de Casearia e Erythroxylum com três espécies cada. Entre os gêneros mais importantes neste estudo, Miconia, Myrcia, Eugenia e Ocotea também se destacaram em outros estudos com o Cerrado (SANO et al., 2008). No Brasil, Ocotea apresenta ampla distribuição, sendo comum em áreas de matas, cerrados, campos rupestres e áreas perturbadas (MORAES, 2005).

O menor índice de diversidade observado no ambiente RASE (Tabela 2) possivelmente se deveu ao fato de $M$. gemmulata estar afetando o estabelecimento de outras espécies, como indicado por Kubota et al. (2005). No estudo das espécies do gênero Mimosa do Novo Mundo, Barneby (1991) citou que as espécies que apresentam vários ramos perfilhandos desde a base, como é o caso 
Tabela 1 - Fitossociologia das espécies arbóreas amostradas em cinco ambientes de reserva florestal em recuperação entre plantios de eucalipto.

Table 1 - Phytosociology of tree species on five environments of forest reserve in recovery among eucalyptus plantations.

\begin{tabular}{|c|c|c|c|c|c|c|c|c|c|c|}
\hline \multicolumn{11}{|c|}{ Recuperação inicial sem eucalipto } \\
\hline Espécie & NI & NP & DA & DR & FA & FR & $\mathbf{A B}$ & DoA & DoR & IVI \\
\hline Mimosa gemmulata & 29 & 2 & 181,25 & 20,42 & 50 & 3,92 & 0,055 & 0,346 & 23,14 & 15,83 \\
\hline Dalbergia miscolobium & 16 & 3 & 100,00 & 11,27 & 75 & 5,88 & 0,029 & 0,187 & 12,49 & 9,88 \\
\hline Ocotea aciphylla & 6 & 4 & 37,50 & 4,23 & 100 & 7,84 & 0,019 & 0,120 & 8,02 & 6,70 \\
\hline Cabralea canjerana & 11 & 2 & 68,75 & 7,75 & 50 & 3,92 & 0,013 & 0,082 & 5,52 & 5,73 \\
\hline Eriotheca gracilipes & 7 & 4 & 43,75 & 4,93 & 100 & 7,84 & 0,010 & 0,065 & 4,37 & 5,71 \\
\hline Heteropterys byrsonimifolia & 11 & 1 & 68,75 & 7,75 & 25 & 1,96 & 0,013 & 0,076 & 5,25 & 4,98 \\
\hline Brosimum gaudichaudii & 4 & 1 & 25,00 & 2,82 & 25 & 1,96 & 0,016 & 0,101 & 6,76 & 3,85 \\
\hline Outros & & & & & & & & & & 47,33 \\
\hline \multicolumn{11}{|c|}{ Recuperação inicial com eucalipto } \\
\hline Espécie & NI & NP & DA & DR & FA & FR & AB & DoA & DoR & IVI \\
\hline Mimosa gemmulata & 20 & 3 & 125,00 & 18,52 & 75 & 5,77 & 0,039 & 0,244 & 17,97 & 14,09 \\
\hline Enterolobium gummiferum & 10 & 3 & 62,50 & 9,26 & 75 & 5,77 & 0,033 & 0,203 & 15,02 & 10,01 \\
\hline Cabralea canjerana & 11 & 3 & 68,75 & 10,19 & 75 & 5,77 & 0,012 & 0,076 & 5,60 & 7,18 \\
\hline Dalbergia miscolobium & 7 & 3 & 43,75 & 6,48 & 75 & 5,77 & 0,018 & 0,117 & 8,62 & 6,96 \\
\hline Stryphnodendron adstringens & 5 & 3 & 31,25 & 4,63 & 75 & 5,77 & 0,011 & 0,072 & 5,30 & 5,23 \\
\hline Couepia grandiflora & 6 & 3 & 37,50 & 5,56 & 75 & 5,77 & 0,006 & 0,039 & 2,91 & 4,74 \\
\hline Ocotea aciphylla & 5 & 2 & 31,25 & 4,63 & 50 & 3,85 & 0,012 & 0,076 & 5,60 & 4,69 \\
\hline Outros & & & & & & & & & & 38,32 \\
\hline \multicolumn{11}{|c|}{ Recuperação avançada sem eucalipto } \\
\hline Espécie & NI & $\mathbf{N P}$ & DA & DR & FA & FR & AB & doa & DoR & IVI \\
\hline Mimosa gemmulata & 113 & 4 & 706,25 & 54,85 & 100 & 7,02 & 0,160 & 1,002 & 40,22 & 34,03 \\
\hline Caryocar brasiliense & 10 & 3 & 62,50 & 4,85 & 75 & 5,26 & 0,064 & 0,398 & 15,97 & 8,69 \\
\hline Ocotea aciphylla & 11 & 3 & 68,75 & 5,34 & 75 & 5,26 & 0,045 & 0,280 & 11,25 & 7,29 \\
\hline Pouteria ramiflora & 9 & 4 & 56,25 & 4,37 & 100 & 7,02 & 0,020 & 0,118 & 4,762 & 5,38 \\
\hline Outros & & & & & & & & & & 34,75 \\
\hline \multicolumn{11}{|c|}{ Recuperação avançada com eucalipto } \\
\hline Espécie & NI & $\mathbf{N P}$ & DA & DR & FA & FR & AB & DoA & DoR & IVI \\
\hline Ocotea aciphylla & 24 & 4 & 150,00 & 9,92 & 100 & 5,33 & 0,115 & 0,717 & 22,01 & 12,42 \\
\hline Enterolobium gummiferum & 23 & 2 & 143,75 & 9,5 & 50 & 2,67 & 0,053 & 0,336 & 10,30 & 7,49 \\
\hline Dalbergia miscolobium & 14 & 3 & 87,50 & 5,79 & 75 & 4,00 & 0,036 & 0,227 & 6,97 & 5,58 \\
\hline Cabralea canjerana & 19 & 3 & 118,75 & 7,85 & 75 & 4,00 & 0,023 & 0,146 & 4,50 & 5,45 \\
\hline Piptocarpha sp. & 14 & 2 & 87,50 & 5,79 & 50 & 2,67 & 0,033 & 0,206 & 6,34 & 4,93 \\
\hline Eriotheca gracilipes & 14 & 3 & 87,50 & 5,79 & 75 & 4,00 & 0,025 & 0,158 & 4,86 & 4,88 \\
\hline Miconia pohliana & 7 & 3 & 43,75 & 2,89 & 75 & 4,00 & 0,035 & 0,221 & 6,80 & 4,56 \\
\hline Mimosa pithecolobioides & 16 & 2 & 100,00 & 6,61 & 50 & 2,67 & 0,022 & 0,139 & 4,28 & 4,52 \\
\hline Chamaecrista sp. & 10 & 1 & 62,50 & 4,13 & 25 & 1,33 & 0,013 & 0,084 & 2,59 & 2,69 \\
\hline Stryphnodendron adstringens & 6 & 2 & 37,50 & 2,48 & 50 & 2,67 & 0,010 & 0,063 & 1,95 & 2,37 \\
\hline Outros & & & & & & & & & & 47,5 \\
\hline \multicolumn{11}{|l|}{ Cerrado sentido restrito } \\
\hline Espécie & NI & $\mathbf{N P}$ & DA & DR & FA & FR & $\mathbf{A B}$ & DoA & DoR & IVI \\
\hline Kielmeyera lathrophytum & 2 & 1 & 12,50 & 5,00 & 25 & 3,70 & 0,323 & 2,019 & 40,70 & 16,47 \\
\hline Caryocar brasiliense & 8 & 3 & 50,00 & 20,00 & 75 & 11,10 & 0,135 & 0,846 & 17,07 & 16,06 \\
\hline Eriotheca gracilipes & 1 & 1 & 6,25 & 2,50 & 25 & 3,70 & 0,287 & 1,796 & 36,21 & 14,14 \\
\hline Kielmeyera coriacea & 2 & 2 & 12,50 & 5,00 & 50 & 7,41 & 0,002 & 0,012 & 0,26 & 4,22 \\
\hline Emmotum nitens & 3 & 1 & 18,75 & 7,50 & 25 & 3,70 & 0,005 & 0,033 & 0,66 & 3,96 \\
\hline Outros & & & & & & & & & & 45,16 \\
\hline
\end{tabular}

${ }^{*} \mathrm{NI}=$ número de indivíduos; $\mathrm{NP}=$ número de parcelas com ocorrência da espécie; DA= densidade absoluta; DR = densidade relativa; $\mathrm{FA}$ = frequência absoluta; $\mathrm{FR}$ = frequência relativa; $\mathrm{AB}$ = área basal; DoA = dominância absoluta; DoR = dominância relativa; e IVI = índice de valor de importância. 
Tabela 2 - Síntese dos parâmetros gerais de estrutura e diversidade entre os diferentes ambientes.

Table 2 - Synthesis of general parameters of structure and diversity among different environments.

\begin{tabular}{|c|c|c|c|c|c|}
\hline Ambientes & RISE & RICE & RASE & RACE & CERRADO \\
\hline Número de indivíduos & 142 & 108 & 206 & 242 & 40 \\
\hline Densidade total ( $\mathrm{N}^{\circ}$ ind/ha) & 906,25 & 675 & 1287,5 & 1512,5 & 250 \\
\hline Área basal $\left(\mathrm{m}^{2} / \mathrm{ha}\right)$ & 0,236 & 0,217 & 0,399 & 0,521 & 0,794 \\
\hline Diâmetro médio (cm) & 4,30 & 4,60 & 4,60 & 4,80 & 6,6 \\
\hline Altura média (m) & 1,98 & 2,17 & 2,06 & 2,78 & 4,03 \\
\hline Número de espécies & 36 & 34 & 39 & 52 & 24 \\
\hline Número de famílias & 23 & 17 & 25 & 25 & 19 \\
\hline Equabilidade (J) & 0,84 & 0,86 & 0,59 & 0,86 & 0,92 \\
\hline Índice de Shannon (H’) & 3,021 & 3,039 & 2,145 & 3,375 & 2,935 \\
\hline
\end{tabular}

*RISE = ambiente de recuperação inicial sem eucalipto, RICE = ambiente de recuperação inicial com eucalipto, RASE = ambiente de recuperação avançada sem eucalipto, RACE = ambiente de recuperação avançada com eucalipto e CERRADO = Cerrado sentido restrito.

de $M$. gemmulata, são oportunistas, ocorrendo em áreas abertas, com maior intensidade de competição por água do que por luz. Dessa forma, a presença do eucalipto pode ser o fator determinador da baixa importância dessa espécie no ambiente RICE, ou sua ausência nos ambientes RACE, o mesmo acontecendo no Cerrado.

Possivelmente, o maior índice de valor de importância de M. gemmulata, em RASE, considerada espécie pioneira (BARNEBY, 1991), interferiu no estabelecimento de maior número de espécies. Já o maior número de espécies em RACE (Tabela 2), culminando com os maiores índices de diversidade e equabilidade entre todos os ambientes, provavelmente indicou que o eucalipto favorece maior complexidade ambiental e sua retirada pode ocasionar mortalidade de indivíduos menores, causando diminuição na diversidade local.

A remoção ou não do eucalipto na regeneração inicial não afetou a diversidade nesses ambientes, entretanto a remoção do eucalipto no estádio avançado promoveu redução da diversidade, ao permitir a colonização por espécies pioneiras como $M$. gemmulata, além do possível dano causado às demais espécies. Entretanto, a manutenção do eucalipto na recuperação avançada resultou nos maiores valores de diversidade e demais atributos estruturais.

Os dados evidenciam a preocupação com a infestação de M. gemmulata em área recém- cultivada com o eucalipto. Dessa forma, que sejam utilizadas medidas culturais e preventivas. Como método de controle cultural, observouse a necessidade nesses ambientes em recuperação do manejo de plantas infestantes. Esse deve ser feito através de um programa de manejo em longo prazo ou até que a vegetação exerça sua influência sobre o angiquinho, principalmente sombreando o ambiente e diminuindo, assim, o crescimento da infestante.
Práticas culturais durante a época de plantio podem ser importantes, de forma que diminua a futura infestação, considerando, sobretudo, a biologia, morfologia de crescimento e desenvolvimento da espécie em questão. Porém, medidas preventivas também devem ser consideradas, principalmente dois aspectos: em primeiro lugar, impedir que as populações de plantas daninhas presentes aumentem suas populações e, em segundo lugar, evitar a introdução de novos propágulos. No primeiro caso, as medidas para condução das culturas ajudam a diminuir a capacidade reprodutiva das plantas daninhas. Outras medidas complementares possíveis devem ser trabalhadas, sobretudo, em nível de comunidades, como no caso do angiquinho, impedindo também o desenvolvimento de plantas indesejáveis nas áreas adjacentes à cultura.

As diferentes espécies de plantas daninhas apresentaram distintas capacidades de interferência sobre a cultura, devendo-se esperar maior capacidade de interferência de plantas de maior porte (PITELLI, 1985). Levando esse fato em consideração, pode-se inferir que a pressão de interferência exercida pelo angiquinho é maior, uma vez que nos estágios iniciais apresentam porte mais elevado, além de desenvolver-se mais rapidamente que as outras plantas, assim com o eucalipto, por apresentar hábito de crescimento como espécie pioneira.

Hábito de crescimento prostrado de algumas espécies representa capacidade de interferência, como da erva-quente (Spermacoce latifolia), que foi muito importante na composição total da comunidade infestante e pode interferir negativamente sobre o crescimento do eucaliptal ou do ambiente em que se deseja reestabelecer, conforme constataram Costa et al. (2002). 
Quando se analisou a interferência dessa comunidade infestante, em função dos períodos de convivência, sobre o crescimento em altura e em diâmetro, não se verificou efeito significativo. Toledo et al. (2000), avaliando o efeito da faixa de controle de plantas daninhas sobre o desenvolvimento inicial de plantas de $E$. grandis x E. urophylla, em que a densidade 16,5 plantas.m 2 justificou a utilização de controle químico destas. Quando a nutrição mineral passou a ser fator limitante ao crescimento das plantas, não mais se constatou efeito das competições. E. urophylla precisa permanecer livre da interferência das plantas daninhas (basicamente capim-braquiária e erva-quente) até os 140 dias após o plantio das mudas, sendo a interferência da comunidade infestante com predomínio de capim-braquiária minimizada com faixas de controle de, no mínimo, $100 \mathrm{~cm}$ de cada lado das mudas (TOLEDO et al., 2000).

\section{CONCLUSÃO}

O estudo da composição florística e estrutural da vegetação argustivo-arbórea pode mostrar que o plantio de eucalipto em extensas áreas de Cerrado promove redução da biodiversidade em relação ao Cerrado. Contudo, a retirada das plantas de eucalipto, no intuito de restabelecer a vegetação do Cerrado, favorece o estabelecimento de vegetação com baixa diversidade de espécies, com infestação de poucas espécies agressivas, com destaque para o angiquinho (M. gemmulata). Entretanto, áreas após o plantio de eucalipto, em que se pretendia preservar para a criação dos corredores ecológicos, apresentam maior diversidade quando na presença do eucalipto. Esse método, além de controlar o crescimento desordenado de $M$. gemmulata, cria um ambiente favorável para o crescimento e desenvolvimento de espécies pioneiras até que se estabeleçam estágios de sucessões mais avançados nos corredores ecológicos, aumentando a biodiversidade local.

\section{REFERÊNCIA}

APG III. An update of the Angiospem Phylogeny Group classification for the orders and families of flowering plants: APG III. Botanical Journal of the Linnean Society, v.161, n.2, p.105-121, 2009.

BARNEBY, R. C. Sensitivae Censitae: A description of the genus Mimosa Linnaeus (Mimosaceae) in the New World. New York: The New York Botanical Garden, 1991. 835p. (Memoirs of New York Botanical Garden, v.65).
BUHLER, D. D.; HARTZLER, R. G.; FORCELLA, F. Implications of weed seedbank dynamics to weed management. Weed Science, v.45, p.329-336, 1997.

BRASIL. Ministério do Planejamento e Orçamento. Fundação Instituto Brasileiro de Geografia e Estatística. Diagnóstico ambiental da bacia do rio Jequitinhonha. Salvador: IBGE/Diretoria de Geociências, 1997.

BROWN, S.; LUGO, A. E. Tropical secondary forests. Journal of Tropical Ecology, v.6, n.1, p.1-32, 1990.

COSTA, A. G. F.; ALVES, P. L. C. A.; PAVANI, M. C. M. D. Períodos de interferência de erva-quente (Spermacoce latifolia) no crescimento inicial de eucalipto (Eucalyptus grandis). Scientia Forestalis, n.61, p.103-112, 2002.

FELFILI, J. M.; SILVA JÚNIOR, M. C.

Biogeografia do Bioma Cerrado: estudo fitofisionômico na Chapada do Espigão Mestre do São Francisco. Brasília: Universidade de Brasília, 2003.152p.

FERNÁNDEZ-QUINTANILLA, C. et al. Ecologia de lãs malas hierbas. In: GARCIA TORRES, L.; FERNÁNDEZ QUINTANILLA, C. Fundamentos sobre malas hierbas y herbicidas. Madrid: MundiPrensa, 1991. p.49-69.

FINEGAN, B. Forest succession. Nature, v. 312, n. 5990, p. 109-114, 1984.

FORMAN, L.; BRIDSON, D. The herbarium handbook. Kew: Royal Botanic Gardens, 1989. 214p.

GRAU, H. R. et. al. Floristic and structural patterns along a chronosequence of secondary forest succession in Argentinean subtropical montane forests. Forest Ecology and Management, v.95, n.2, p.161-171, 1997.

KUBOTA, Y.; KATSUDA, K.; KIKUZAWA, K. Secondary succession and effects of clear-logging on diversity in the subtropical forests on Okinawa Island, southern Japan. Biodiversity and Conservation, v.14, n.4, p.879-901, 2005.

MENDONÇA, R. C. et al. Flora Vascular do Cerrado. In: SANO S.M.; ALMEIDA, S.P. (Ed.). Cerrado: flora, homem e ambiente. Planaltina: Embrapa Cerrados, 1998. p. 217-396.

Revista Árvore, Viçosa-MG, v.38, n.3, p.415-422, 2014 
MONQUERO, P. A.; CHRISTOFFOLETI, P. J. Dinâmica do banco de sementes em áreas com aplicação frequente do herbicida glyfosate.

Planta Daninha, v.21, n.1, p.63-69, 2003.

MORAES, P. L. R. Sinopse das Lauráceas nos estados de Goiás e Tocantins, Brasil. Biota Neotropica, v.5, n.2, p.253-270, 2005.

NERI, A. V. et al. Análise da estrutura de uma comunidade lenhosa em área de cerrado sensu stricto no município de Senador Modestino Gonçalves, norte de Minas Gerais, Brasil.

Revista Árvore, v.31, n.1, p.123-134, 2007.

OLIVEIRA FILHO, A. T. et al. Diversity and structure of the tree community of a fragment of tropical secondary forest of the Brazilian Atlantic Forest domain 15 and 40 years after logging. Revista Brasileira de Botânica, v.27, n.4, p.685-701, 2004.

PAULA, A. et al. Sucessão ecológica da vegetação arbórea em uma Floresta Estacional Semidecidual, Viçosa, MG, Brasil. Acta

Botanica Brasílica, v.18, n.3, p.407-423, 2004.

PEDRALLI, G. Macrófitas aquáticas como bioindicadoras da qualidade de água: alternativas para usos múltiplos de reservatórios. In: THOMAZ, S. M.; BINI, L. M. (Ed.). Ecologia e manejo de macrófitas aquáticas.

Maringá: Universidade Estadual de Maringá, 2003. p.171-188.

PINHEIRO, E. S.; DURIGAN, G. Diferenças florísticas e estruturais entre fitofisionomias do cerrado em Assis, SP, Brasil. Revista Árvore, v.36, n.1 p.181-193, 2012.

PITELLI, R. A. Interferência de plantas daninhas em culturas agrícolas. Informe

Agropecuário, v.1, n.129, p.16-27, 1985.
RAMSAR, COP7 DOC.24. Invasive Species and wetlands. The Ramsar Convention on Wetlands. Backgraund document: 12/01/01. Disponível em: http://www.ramsar.org/cda/en/ ramsar-documents-resol-resolution-vii-14/main/ ramsar/1-31-107\%5E20830_4000_0_. Acesso em: 05 jun. 2012.

RIBAS, R. F. et al. Composição florística de dois trechos em diferentes etapas serais de uma floresta estacional semidecidual em viçosa, Minas Gerais Revista Árvore, v.27, n.6, p.821-830, 2003.

RIBEIRO, J. F.; WALTER, B. M. T. Fitofisionomias do bioma Cerrado. In: SANO, S. M.; ALMEIDA, S. P. (Ed.). Cerrado ambiente e flora.

Planaltina: Embrapa-Cerrados, 1998. p.89-166.

SANO, S. M.; ALMEIDA, S. P.; RIBEIRO, J. F. Cerrado: ecologia e flora. Brasília: Embrapa, 2008. v.2. 1284 p.

SANTOS, S. B.; PEDRALLI, G.; MEYER, S. T. Aspectos da fenologia e ecologia de Hedychium coronarium (Zingiberaceae) na estação ecológica do Tripuí, Ouro Preto-MG. Planta Daninha, v. 23, n. 2, p.175-180, 2005.

SOUZA, L. S. A.; SILVA, J. F.; SOUZA, M. D. B. Composição florística de plantas daninhas em agrossistemas de cupuaçuzeiro (Theobroma grandiflorum) e pupunheira (Bactris gasipaes). Planta Daninha, v.21, n.2, p.249-255, 2003.

TOLEDO, R. E. B. et al. Efeitos da faixa de controle do capim-braquiária (Brachiaria decumbens) no desenvolvimento inicial de plantas de eucalipto. Planta Daninha, v.18, n.3, p.383-393, 2000.

VOLL, E. et al. Dinâmica do banco de sementes de plantas daninhas sob diferentes sistemas de manejo do solo. Planta Daninha, v.19, n.2, p.171-178, 2001. 